\title{
Irradiation leads to apoptosis of Kupffer cells by a Hsp27-dependant pathway followed by release of TNF- $\alpha$
}

\author{
K. Tello $\cdot$ H. Christiansen $\cdot$ H. Gürleyen $\cdot$ J. Dudas $\cdot$ \\ M. Rave-Fränk · C. F. Hess · G. Ramadori · B. Saile
}

Received: 30 December 2007 / Accepted: 22 April 2008 / Published online: 21 May 2008

(C) The Author(s) 2008

\begin{abstract}
In a previous publication, we were able to show that irradiation of Kupffer cells, the liver resident macrophages, leads to an increased TNF- $\alpha$ concentration in the culture medium. The pathomechanisms underlying this phenomenon, however, remained to be elucidated. Here, we show that following irradiation of Kupffer cells, the apoptosis rate increased drastically within $48 \mathrm{~h}$. At the same time, the total TNF- $\alpha$ concentration in cell lysates of Kupffer cells attached to the culture plate decreased. However, normalization of the TNF- $\alpha$ concentration with respect to cell number revealed that TNF- $\alpha$ concentration per attached cell remained constant during the observation period. Western blot analysis showed that heat shock protein 27 (Hsp27) is strongly downregulated and bax is upregulated in irradiated Kupffer cells as compared to sham-irradiated cells. Overexpression of Hsp27 in Kupffer cells was shown to prevent the effect of irradiation on bax expression, apoptosis and, at the same time, on increase of TNF- $\alpha$ concentration in the Kupffer cell medium. We conclude that irradiation of Kupffer cells leads to apoptosis because of downregulation of $\mathrm{Hsp} 27$ and consecutive upregulation of bax expression. Furthermore, we suggest that apoptosis of Kupffer cells leads to an increase of TNF$\alpha$ concentration in the culture medium which may be due to cell death rather than active release or synthesis.
\end{abstract}

\footnotetext{
K. Tello · H. Gürleyen · J. Dudas · G. Ramadori · B. Saile ( $\square)$ Department of Internal Medicine,

Section of Gastroenterology and Endocrinology, Georg-August-University Göttingen,

Robert-Koch-Straße 40, 37075 Göttingen, Germany

e-mail: bsaile@gwdg.de

H. Christiansen · M. Rave-Fränk · C. F. Hess

Department of Radiation Oncology,

University of Göttingen, Göttingen, Germany
}

\section{Introduction}

The liver is a highly radiosensitive organ because of the danger of development of radiation-induced liver disease (RILD). However, the pathophysiological mechanisms of hepatocellular cell death after liver irradiation in vivo are widely unknown. Moreover, isolated primary hepatocytes in vitro are known to be radioresistant [1-3, 23-26]. In previous studies, we demonstrated that conditioned medium of irradiated Kupffer cells, the liver resident macrophages, leads to apoptotic cell death of irradiated hepatocytes, which results mainly from increased TNF- $\alpha$ in the medium [12]. The aim of the present study was to elucidate the mechanisms underlying the increased TNF- $\alpha$-release of Kupffer cells after irradiation.

In a preliminary work, a rat-specific cDNA gene expression array showed that the expression of heat shock protein 27 (Hsp27) was downregulated and the pro-apoptotic member of the bcl-family, bax, was upregulated after irradiation of Kupffer cells. No other Hsps like Hsp90 or Hsp60, nor other members of the apoptosis regulating bcl system (bcl2 , bid) or other apoptosis-relevant proteins like p53, $\mathrm{p} 21^{\mathrm{WAF} 1}, \mathrm{NF} \kappa \mathrm{B}$ or $\mathrm{I} \kappa \mathrm{B}$ were found to exhibit altered expression after irradiation in Kupffer cells.

The Hsp27 belongs to the family of small stress proteins that are constitutively abundant and ubiquitously present. Hsp27 was shown to regulate apoptosis through its ability to interact with key components of the apoptosis-signalling pathways (reviewed in [15]), particularly those involved in caspase activation. Changes in the intracellular redox balance and production of reactive oxygen species initiate the apoptotic cascade through changes in the mitochondria and release of pro-apoptotic factors. Hsp27 can maintain both the redox homeostasis and mitochondrial stability in the cell. Increased expression of Hsp27 during stress response 
correlates with better survival from cytotoxic stress. It negatively regulates the activation of procaspase 9 by sequestering cytosolic cytochrome $c$ from Apaf-1, after its release from mitochondria and thus, prevents assembly of the apoptosome [9, 14]. Hsp27 was shown to block the release of cytochrome $c$ from mitochondria in cells exposed to staurosporine, etoposide or cytochalasin D [35]. It also mediates inhibition of procaspase 3 activation, most likely through its ability to prevent initiator caspases like caspase 9 from gaining access to the residues whose cleavage is essential for procaspase 3 activation [34]. In addition, Hsp27 maintains the actin network integrity and hence, prevents translocation of pro-apoptotic factors like activated Bid (tBid) onto the mitochondrial membrane [35]. Hsp27 is reported to block DAXX-mediated apoptosis by preventing its translocation to the membrane and thus, inhibit its interaction with Fas and ASK-1 [10]. Rane et al. have suggested that Hsp27 regulates apoptosis of neutrophils through interaction with Akt (Protein Kinase B): Hsp27 is phosphorylated by Akt, which results in dissociation of Hsp27 and stabilization of Akt. Disruption of interaction between Akt and Hsp27 impairs Akt activation, which leads to enhanced constitutive apoptosis of neutrophils [37]. The only known pro-apoptotic role of Hsp27 so far is that it enhances TNFinduced apoptosis by inhibiting $\mathrm{I} \kappa \mathrm{B}$ degradation and thereby, prevents $\mathrm{NF} \kappa \mathrm{B}$ mediated cell survival [27]. Our data on Kupffer cells suggest a further action: Irradiation leads to downregulation of Hsp27 and to an upregulation of the proapoptotic bax leading to apoptosis and release of TNF- $\alpha$.

\section{Materials and Methods}

Animals

Male Wistar rats (200-260 g) were kept on a 12-h day/ night rhythm (light from 07:00-19:00 hours) with free access to water and food. Rats were anesthetized with pentobarbital ( $60 \mathrm{mg} \mathrm{kg}^{-1}$ body weight) before preparation of Kupffer cells between 08:00 and 09:00 hours. The study protocols were approved by a government review board. All animals received care in compliance with institutional guidelines, the German Convention for Protection of Animals and the National Institutes of Health guidelines.

\section{Cell culture}

Kupffer cells were isolated according to the method of De Leeuw [17] with modifications as described previously [28, 33]. Liver macrophages were plated using 200,000 cells per $\mathrm{ml}$ of culture medium [M-199 (Biochrom) supplemented with 10\% FCS (PAA)]. Purity of the cell isolation was determined by ED1/ED2 staining. The medium was replaced $24 \mathrm{~h}$ after isolation directly before irradiation.

Irradiation

Kupffer cells, on the first day after isolation were irradiated with $6 \mathrm{MV}$ photons at a dose rate of $2.4 \mathrm{~Gy} \mathrm{~min}^{-1}$ using a Varian Clinac $600 \mathrm{C}$ accelerator (Varian, Palo Alto, CA, USA). Single doses of 2 or 8 Gy were applied. For shamirradiation, Kupffer cells were kept exactly the same time outside the incubator and in the same room as done for irradiation with 2 or $8 \mathrm{~Gy}$.

Flow cytometric and fluorescence microscopic quantification of living, apoptotic and necrotic Kupffer cells

For quantification of apoptotic cells we used flow cytometry after trypsination of Kupffer cells (Epics ML, Coulter, Kerfeld, Germany). To detect apoptotic changes staining with Annexin V-FITC/propidiumiodide and the TUNEL method (Tdt-mediated X-dUTP nick end labelling) were used (Boehringer, Mannheim, Germany). Annexin V and PI negative cells were assessed as healthy living cells, Annexin V positive but PI negative cells as apoptotic cells, Annexin V and PI positive cells as necrotic cells and Annexin V negative but PI positive as cell detritus. To additionally assess survival of Kupffer cell cultures Trypan blue dye exclusion test was used after trypsination of the cell cultures.

cDNA probe

A PCR-generated cDNA directed against rat TNF- $\alpha$ mapping positions $140-509$ of the published sequence was used [19]. Northern blot results were normalized with respect to an oligonucleotide probe specific for chicken $\alpha$-actin cDNA that exhibits cross-reactivity to $\beta$ - and $\gamma$-actin, which was a gift from Schwartz [38].

\section{Northern blot analysis of total RNA}

After collection of the Kupffer cells (attached to the culture plate and cells in the supernatant), total RNA was isolated according to Chirgwin [11] and was separated by agarose gel electrophoresis, transferred onto nylon membranes and hybridized with specific ${ }^{32} \mathrm{P}$ dCTP or ${ }^{32} \mathrm{P}$ dATP labelled cDNA probes as described [33]. cDNA probes were labelled by Random priming ${ }^{\circledR}$ (Stratagene, Heidelberg, Germany). Hybridization was carried out over $2 \mathrm{~h}$ at $68^{\circ} \mathrm{C}$ using the Quick Hyb ${ }^{\circledR}$ solution (Stratagene, Heidelberg, Germany). Post-hybridization washes were performed twice for $15 \mathrm{~min}$ at room temperature and twice for $5-15 \mathrm{~min}$ at $50^{\circ} \mathrm{C}$ in $2 \times$ SSC containing $0.1 \%$ sodium dodecyl sulfate (SDS). 
Nylon filters were exposed to X-ray films at $-80^{\circ}$ and finally densitometric scans were performed.

\section{Analysis of cDNA microarray}

For comparing the gene expression profiles between the sham-irradiated and irradiated Kupffer cells in preliminary work rat specific Atlas cDNA arrays (Atlas Rat 1.2 Array, BD Biosciences Clontech, Palo Alto, CA, USA) were used according to the manufacturer's instructions.

Western blot analysis

Cells at different times after irradiation were lysed in hot Laemmli buffer $\left(95^{\circ} \mathrm{C}\right)$ and processed by SDS-polyacrylamide gel electrophoresis under reducing conditions according to Laemmli [29]. The protein content of cellular lysates was calculated by the Coomassie Protein Assay (Pierce, Rockfort, IL, USA). Proteins were transferred onto Hybond-ECL nitrocellulose hybridization transfer membranes (GE Healthcare, Freiburg, Germany) according to Towbin et al. [43]. Immunodetection was performed according to the ECL Western blotting protocol. Antibodies against bax (Cat. No. PC66) or Hsp27 (Cat. No. CA1025) (Calbiochem, Frankfurt, Germany) were used at $2.5 \mu \mathrm{g} \mathrm{ml}^{-1}$ solutions, and peroxidase-labelled anti-mouse (Cat. No. DC022L) and anti-rabbit immunoglobulins (Cat. No. DC03L) (Calbiochem, Frankfurt, Germany) were each used at a 1/1000 dilution. Equal loading was assessed using antibodies against $\beta$-actin (Cat. No. 1978) (Sigma, Deisenhofen, Germany) at a 1/5000 dilution. Densitometric evaluation of the blots was performed using the program Scion Image Ver. Beta 2 (NIH).

\section{TNF- $\alpha$ ELISA}

For detection of cell-associated TNF- $\alpha$ in Kupffer cells by ELISA, we used Quantikine ELISA kits by R\&D systems. After aspiration of culture medium, plates were washed twice. The Kupffer cells were then disrupted using a lysis buffer, and material was scraped with a rubber policeman. The lysis buffer consisted of $50 \mathrm{mM}$ Tris, $150 \mathrm{mM} \mathrm{NaCl}$, and $1 \%$ Nonidet P-40, pH 7.4. Lysed cellular material was centrifuged at $10,000 \mathrm{~g}$ for $15 \mathrm{~min}$ and the supernatant was assayed for TNF- $\alpha$. Each cell-associated TNF- $\alpha$ sample (cell lysates of sham-irradiated or $8 \mathrm{~Gy}$ irradiated Kupffer cells $0,3,6,9,12$ and $24 \mathrm{~h}$ after irradiation) was derived from three wells $(1 \mathrm{ml})$.

\section{Overexpression of Hsp27}

At day 1 of culture, Kupffer cells were transfected with pCMV Hsp27 (Clontech, Palo Alto, CA, USA). Transfec- tion was performed using the Fugene 6 kit of Roche (Indianapolis, IN, USA). In all cases, $3 \mu \mathrm{l}$ of Fugene 6 and $2 \mu \mathrm{g}$ of plasmid vector were used per well. For control transfections, the pCMV expression vector containing the coding sequence of green fluorescent protein was used. The efficiency of the transfections was 60-70\%. After transfection, cells were sham-irradiated. The effect of Hsp27 expression was confirmed by Western blot analysis. By use of TUNEL as well as Annexin V-FITC/propidium iodide FACS analysis, no significant influence of the transfection agent [Fugene (Boehringer, Mannheim, Germany)] and transfection with the control plasmid on apoptosis of rat Kupffer cells could be shown. Subsequently, Kupffer cells were irradiated. Occurrence of apoptosis was measured using the TUNEL-method, while TNF $\alpha$ concentration in the supernatants was measured by ELISA and influence on bax expression was assessed by Western blot analysis. All experiments were repeated at least seven times, and consistent results were obtained in all cases.

\section{Caspase 8 , caspase 3 , and caspase 9 activity}

For detection of active caspase 8, caspase 3, or caspase 9, we used the Active Caspase Set (Pharmingen, Germany). Cell lysates of $5 \times 10^{6}$ cells were applied and active caspases were detected according to the manufacturer's protocol. To evaluate substrate specificity, caspase 3, caspase 8 , and caspase 9 inhibitors (Oncogene, MA, USA) were used according to the manufacturer's protocol.

Statistical analysis

Results are expressed as mean $\pm \mathrm{SD}$. After assessing normal distribution of the data, significance in differences was tested by ANOVA, followed by Bonferroni's post hoc test and $P<0.05$ was considered to be statistically significant.

\section{Results}

Effect of irradiation on cell viability

Single-dose administration of 8 Gy leads to a substantial decrease of living cells, beginning $4 \mathrm{~h}$ after irradiation and even more enhanced at $48 \mathrm{~h}$ (Fig. 1a). In contrast, a single dose of $2 \mathrm{~Gy}$ did not lead to statistically significant alteration of the portion of living cells when compared to shamirradiated Kupffer cells within a time window of $48 \mathrm{~h}$.

In addition, single-dose irradiation at $8 \mathrm{~Gy}$ led to an increase of apoptotic cells from $4.3 \pm 1.2 \%$ up to $60.7 \pm 2.7 \%$ within $48 \mathrm{~h}$. Sham-irradiated cultures showed only an increase from $4.1 \pm 1.3 \%$ to $13 \pm 2.6 \%$ (Fig. 1b). As early as $4 \mathrm{~h}$ after irradiation, apoptosis increase was 

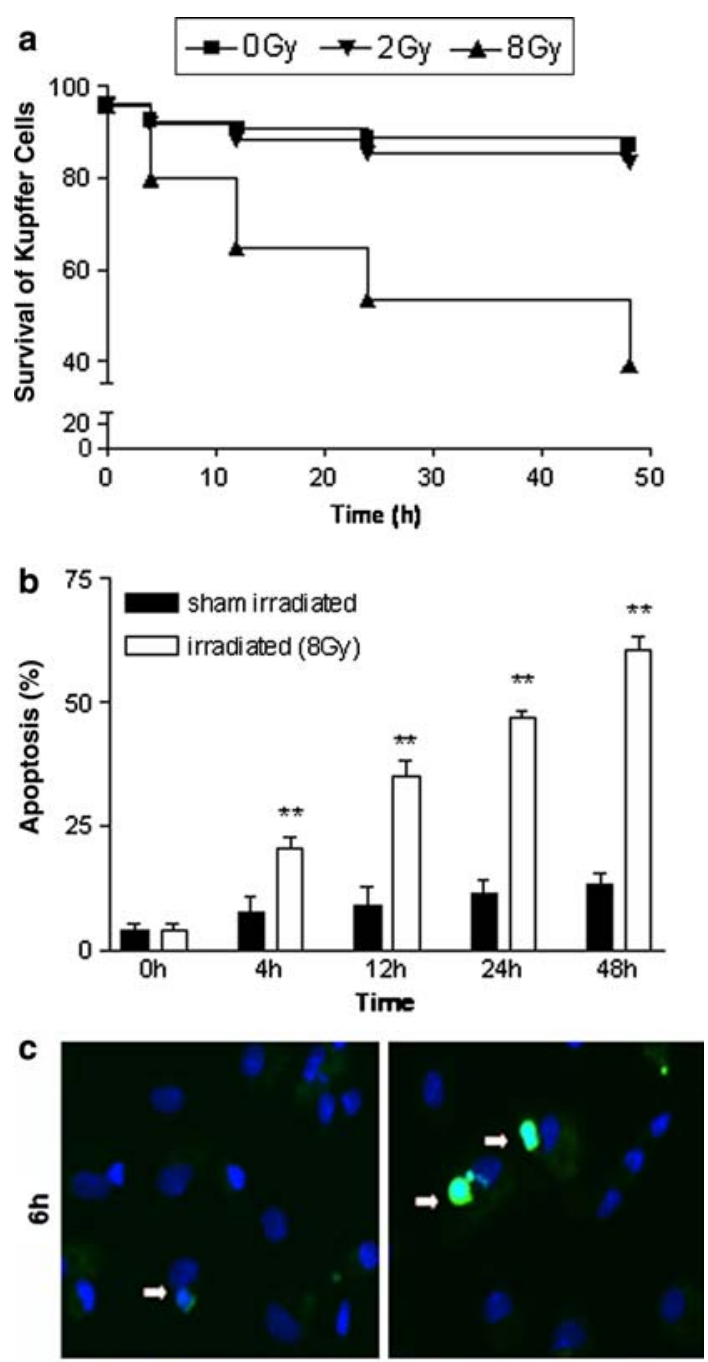

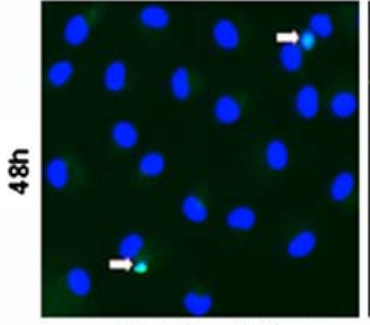

sham irradiation

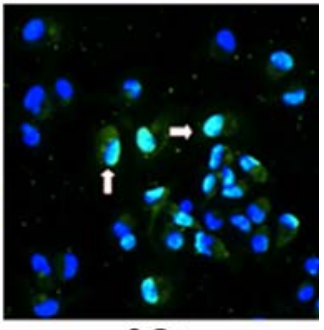

$8 \mathrm{~Gy}$
Fig. 1 a Survival of Kupffer cells irradiated with 2 and 8 Gy (Trypan blue exclusion). The values presented are means of seven independent Kupffer cell isolations. b Apoptosis of Kupffer cells at different time points after irradiation with $8 \mathrm{~Gy}$. For detection of apoptosis the AnnexinV/PI method was used, where cells that bind AnnexinV but do not incorporate propidiumiodide are regarded as apoptotic. Necrotic cells (Annexin V positive and propidiumiodide positive) were always less than $3 \%$. Values presented are means \pm SD of seven independent Kupffer cell isolations. Level of significance of irradiated Kupffer cells compared to the respective sham-irradiated cultures: $* P<0.05$; $* * P<0.01$. c Apoptosis detection using the TUNEL method. Panels presented show Kupffer cells 6 and $48 \mathrm{~h}$ after irradiation at 8 Gy or sham irradiation. Arrows show examples for apoptotic cells. Consistent data could be found in seven independent experiments derived from seven different Kupffer cell isolations statistically significant when using the Annexin V/PImethod, whereas statistically significant differences in apoptosis rates using the TUNEL-method could first be observed $6 \mathrm{~h}$ after irradiation (Fig. 1c). It is noteworthy that the portion of necrotic cells (Annexin $\mathrm{V}$ and propidiumiodide positive cells) was always less than $3 \%$.

\section{Effect of irradiation on TNF- $\alpha$ expression in Kupffer cells}

To test the influence of irradiation on TNF- $\alpha$ gene expression, we first performed Northern-blot analysis using RNA from total Kupffer cell cultures (attached and detached cells) We found TNF- $\alpha$ gene expression to remain unchanged at time points $4,12,24$, and $48 \mathrm{~h}$ after irradiation (Fig. 2a).

To determine cell-associated TNF- $\alpha$ protein levels, after thorough removal of the supernatants and washing of the cultures, Kupffer cells were harvested and cell-associated TNF- $\alpha$ was assessed using ELISA. Whereas TNF- $\alpha$ concentration decreased only slightly in sham-irradiated cultures from $84 \pm 9 \mathrm{pg} \mathrm{ml}^{-1}$ to $70 \pm 10 \mathrm{pg} \mathrm{ml}^{-1}$, a timedependent decrease to $37.8 \pm 6 \mathrm{pg} \mathrm{ml}^{-1}$ was observed within $48 \mathrm{~h}$ in Kupffer cell cultures irradiated at $8 \mathrm{~Gy}$ (Fig. 2b). However, when the TNF- $\alpha$ concentration in Kupffer cells was normalized with respect to cell number, the TNF- $\alpha$ concentration per cell remained constant, regardless of whether the cells were irradiated or not (Fig. 2c). These data strongly suggest that the increase of TNF- $\alpha$ measured in supernatants of irradiated Kupffer cell cultures may be due to a release of TNF- $\alpha$ presumably during apoptosis.

Effect of irradiation on expression of bax and Hsp27 in Kupffer cells

In order to elucidate the mechanism leading to apoptosis and TNF- $\alpha$ release of Kupffer cells after irradiation, in preliminary experiments we used a rat-specific cDNA gene expression array to analyse genes related to cellular stress. Herein, as mentioned in Sect. "Introduction", increase of bax and decrease of Hsp27 were observed. This observation was confirmed by Western blot analysis on protein level (Fig. 3a). As early as $4 \mathrm{~h}$ after irradiation, increase of bax expression and decrease of Hsp27 expression were seen. This effect was even stronger $48 \mathrm{~h}$ after irradiation. In sham-irradiated cultures, no change in either bax or Hsp27expression could be observed (Fig. 3a).

In the next step, we wanted to know whether in Kupffer cells' expression of the proapoptotic bax depends on expression of Hsp27 or is regulated independently. For this purpose, we overexpressed Hsp27 in Kupffer cells. Interestingly, after overexpression of Hsp27 and irradiation, bax 

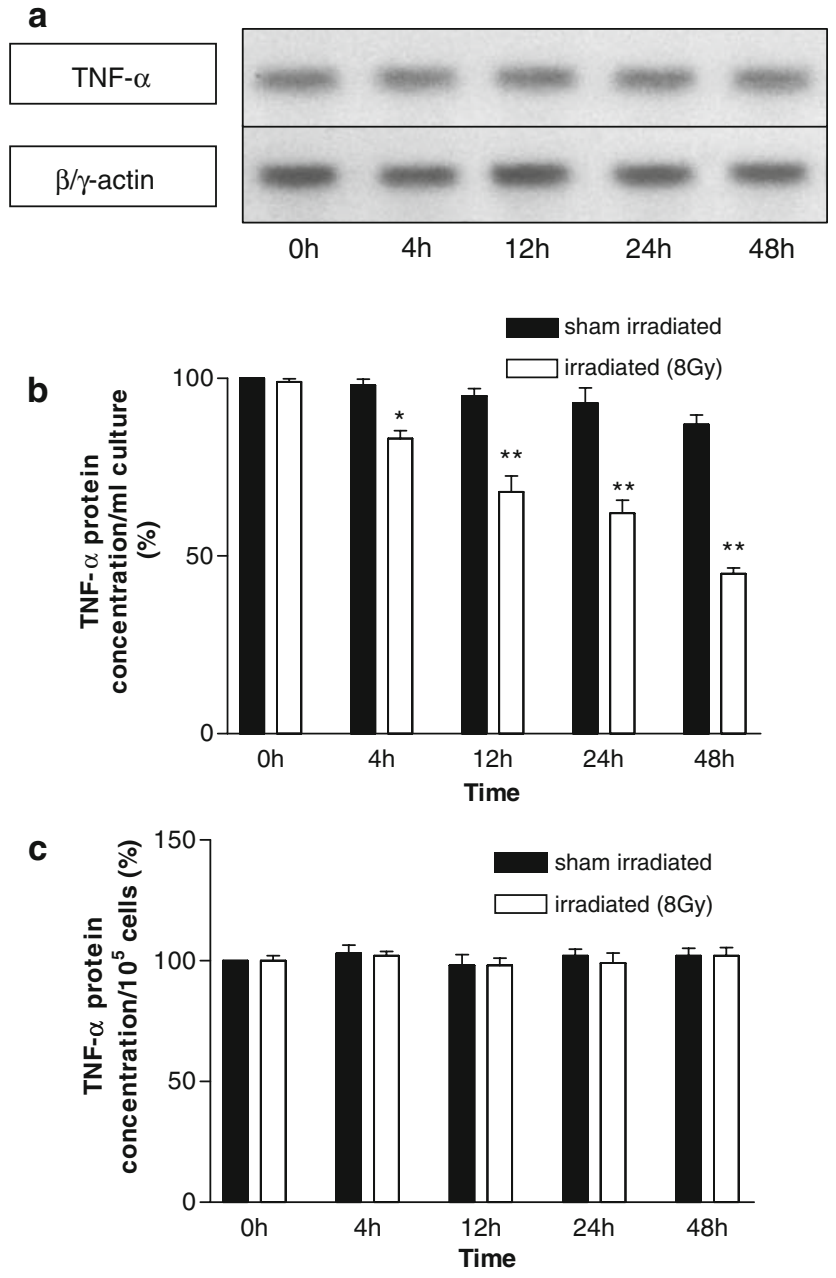

Fig. 2 TNF- $\alpha$ expression in Kupffer cells. a Northern blot analysis of TNF- $\alpha$ mRNA at different time points after irradiation with $8 \mathrm{~Gy} . \beta / \gamma-$ actin gene expression was used as loading control. The blot presented shows representative results for five experiments of five independent isolations. b TNF- $\alpha$ protein concentration per $\mathrm{ml}$ culture of irradiated and sham-irradiated Kupffer cell cultures, as determined by ELISA. The concentration in sham-irradiated cells at time point $0 \mathrm{~h}$ was set as $100 \%$. c TNF- $\alpha$ protein concentration of Kupffer cell cultures, as shown in panel (b), normalized with respect to the number of cells. TNF- $\alpha$ concentration of sham-irradiated Kupffer cell cultures at time point $0 \mathrm{~h}$ was set as $100 \%$. Values presented are means \pm SD of seven independent Kupffer cell isolations. Levels of significance of irradiated Kupffer cells compared to the respective sham-irradiated cultures: $* P<0.05 ; * * P<0.01$

expression was drastically downregulated, suggesting that bax expression in Kupffer cells directly depends on Hsp27 expression (Fig. 3b).

Effect of overexpressing Hsp27 on radiation-induced apoptosis of Kupffer cells and content of TNF- $\alpha$

To gain evidence whether Hsp27 is capable to inhibit radiation-induced apoptosis in Kupffer cells, we overexpressed Hsp27 in Kupffer cells and irradiated the cells with 8 Gy.
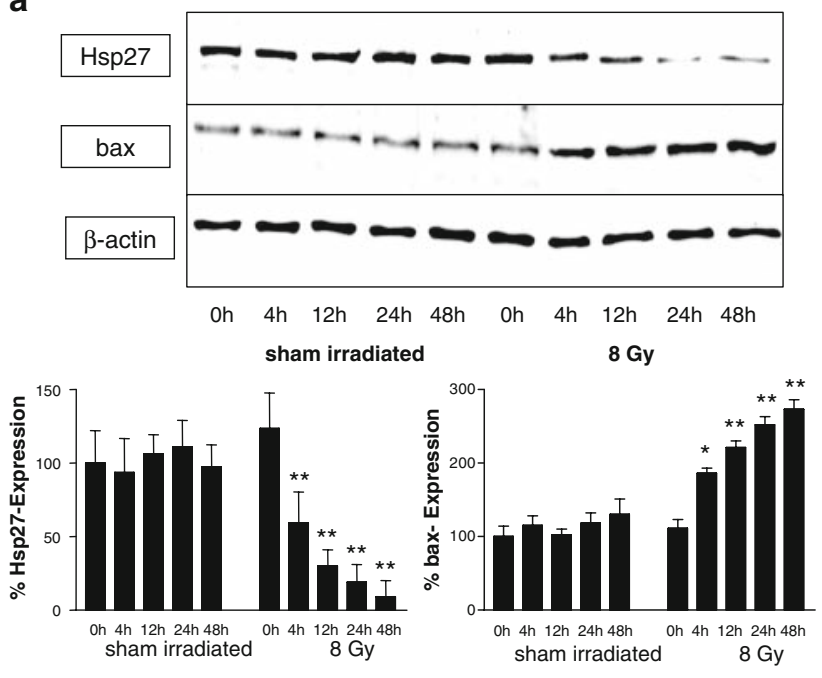

b

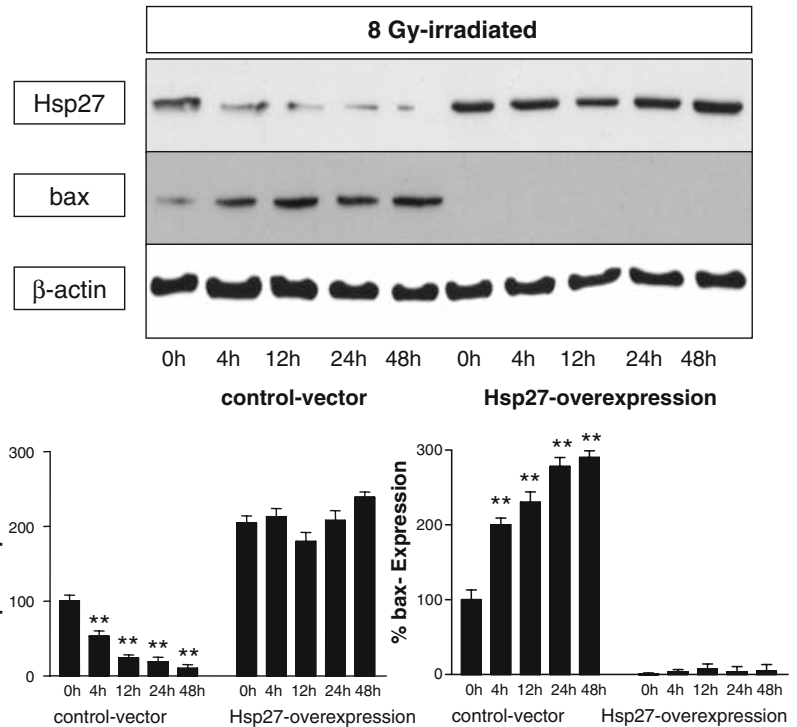

Fig. 3 a Western blot analysis Hsp27, bax and $\beta$-actin in sham-irradiated Kupffer cell cultures and cultures irradiated at $8 \mathrm{~Gy}$ at different time points. The blot presented shows representative results. The lower graphs show densitometric analyses of the Western blot data $(n=5$ derived from five independent Kupffer cell isolations), normalized to $\beta$ actin expression. Level of significance of Kupffer cells at different time points compared to the respective data at time point $0 \mathrm{~h}$ : $* P<0.05$; $* * P<0.01$. b Western blot analysis of Kupffer cells irradiated at $8 \mathrm{~Gy}$ and transfected either with the control vector or the Hsp27 expression vector. Transfection was initiated $12 \mathrm{~h}$ prior to irradiation. Transfection efficiency was $60-70 \%$. The blot shows representative results from seven experiments with seven independent isolations. The lower graphs show densitometric analyses of the Western blot data $(n=7$ derived from seven independent Kupffer cell isolations) normalized on $\beta$ actin expression. Level of significance of Kupffer cells at different time points compared to the respective data at time point $0 \mathrm{~h}$ : $* P<0.05$; $* * P<0.01$

Transfection with a control vector did not alter cellular survival (Fig. 4a) or apoptosis rates of sham-irradiated cultures when compared to non-transfected cells (Fig. 4b). Transfection with the expression vector had very little effect on 

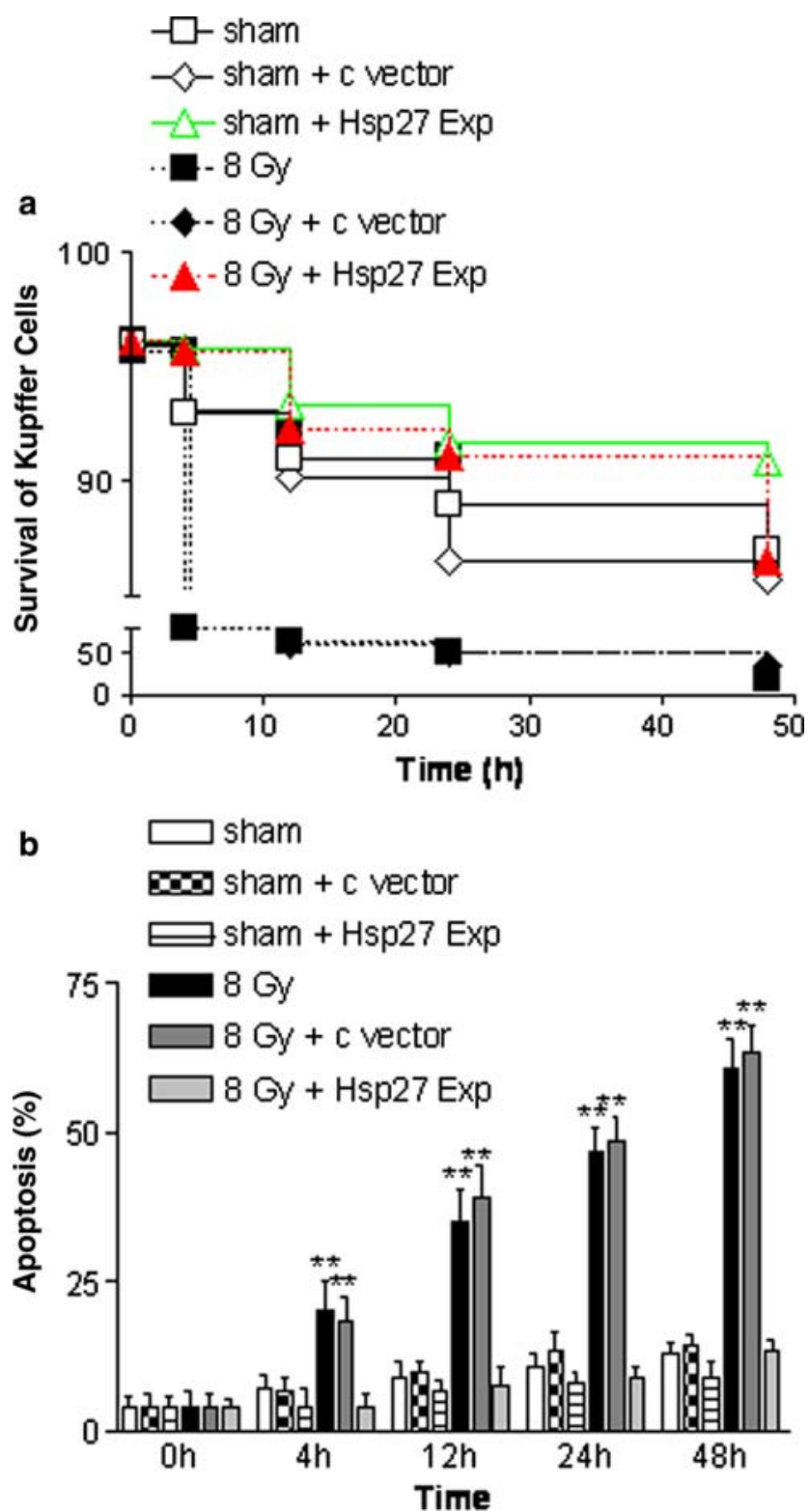

Fig. 4 a Survival of Kupffer cells which were transfected either with the control vector or the Hsp27 expression vector (Trypan blue exclusion after sham-irradiation and irradiation with at $8 \mathrm{~Gy}$ (c vector $=$ empty control vector; Hsp27 Exp $=$ Hsp27 expression vector). The values presented are mean values of seven independent $\mathrm{Ku}-$ pffer cell isolations. b Apoptosis of Kupffer cells. (c vector = empty control vector; Hsp27 Exp = Hsp27 expression vector) as measured by the AnnexinV/propidiumiodide method. Transfection was initiated $12 \mathrm{~h}$ prior to irradiation. Values presented are means \pm SD of seven independent Kupffer cell isolations. Level of significance: $* * P<0.01$

survival and apoptosis in sham-irradiated cultures (Fig. 4b). However, after irradiation overexpression of Hsp27 substantially increased cellular survival (Fig. 4a) and reduced radiation-induced increase of apoptosis to apoptosis levels observed in sham-irradiated cells (Fig. 4b).

It is noteworthy, that overexpression of Hsp27 also completely reversed the TNF- $\alpha$-content in the cultures to levels sham

inim sham + c vector

E sham + Hsp27 Exp

$8 \mathrm{~Gy}$

$8 \mathrm{~Gy}+\mathrm{c}$ vector

$8 \mathrm{~Gy}+\mathrm{Hsp} 27 \mathrm{Exp}$

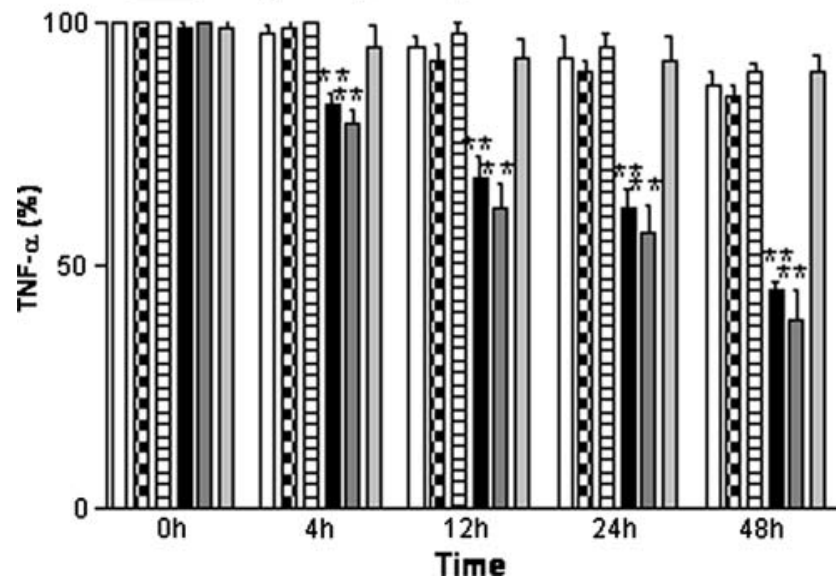

Fig. 5 Effect of Hsp27 overexpression on radiation-induced decrease of cell associated TNF- $\alpha$ in Kupffer cell cultures (c vector $=$ empty control vector; Hsp27 Exp $=$ Hsp27 expression vector). Transfection was initiated $12 \mathrm{~h}$ prior to irradiation. TNF- $\alpha$ content of Kupffer cell cultures at $0 \mathrm{~h}$ was set as $100 \%$. Values presented are means $\pm \mathrm{SD}$ of seven independent Kupffer cell isolations. Level of significance: $* * P<0.01$

measured after sham-irradiation $\left[87 \pm 8 \mathrm{pg} \mathrm{ml}^{-1}(48 \mathrm{~h})\right]$ (Fig. 5). When cell-associated TNF- $\alpha$ content was normalized with respect to the number of living cells, however, constant values were observed (data not shown). These data strongly suggest that radiation-induced apoptosis of Kupffer cells is implemented by downregulation of Hsp27, and overexpression of Hsp27 can prevent Kupffer cells from radiation-induced apoptosis. Moreover, apoptosis of the Kupffer cells seems to be necessary for the observed TNF- $\alpha$ release.

Effect of overexpressing Hsp27 and irradiation on activity of caspase 8, 9, and 3 in Kupffer cells

To further support the hypothesis that during radiationinduced apoptosis of Kupffer cells Hsp27 is involved in the regulation of the mitochondrial pathway of apoptosis, we evaluated the activities of caspase 8 , caspase 9 , and caspase 3. Neither irradiation nor overexpression of Hsp27 led to a changes in the activity of caspase 8, indicating that apoptosis of Kupffer cells after irradiation is not mediated by a pathway that includes activation of a death receptor (Fig. 6a). On the other hand, irradiation led to a timedependent increase of caspase 9 activity, thus demonstrating that the mitochondrial apoptosis pathway may be 

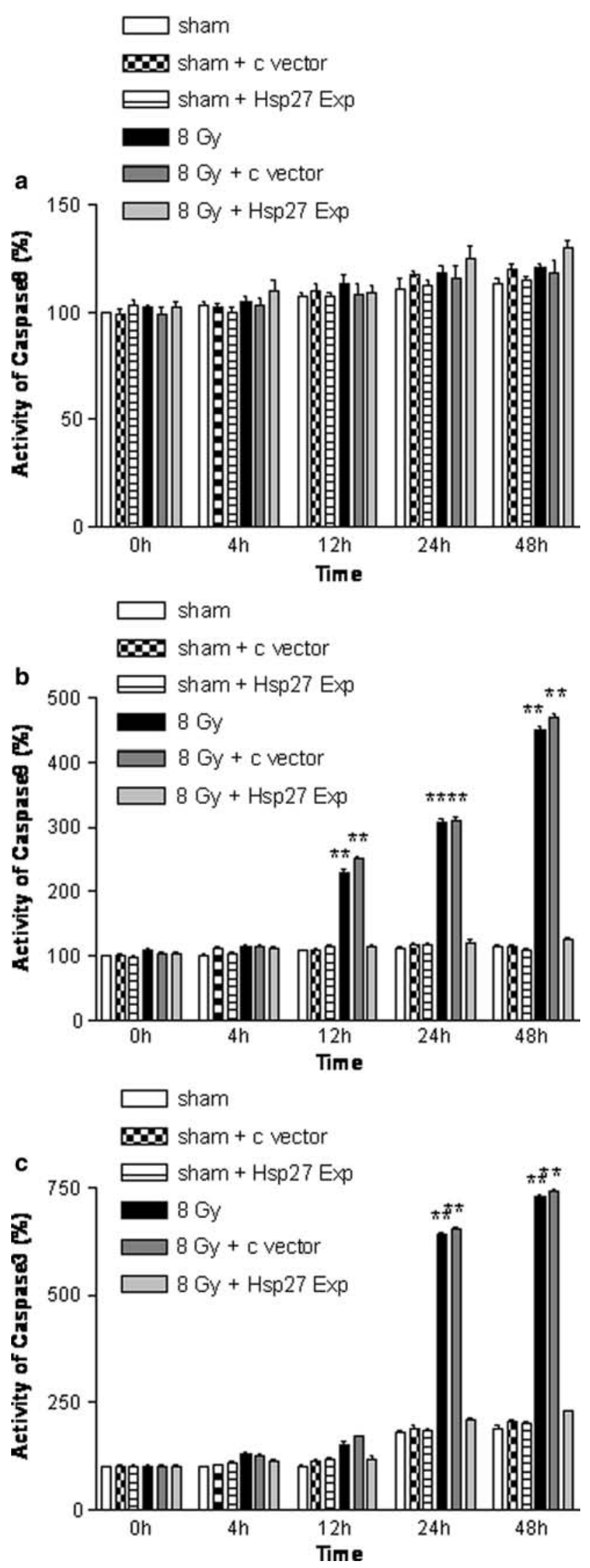

Fig. 6 Activity of caspase 8 (a), caspase 9 (b) and caspase 3 (c) in Kupffer cell cultures. (c vector $=$ empty control vector; Hsp27 Exp $=$ Hsp27 expression vector.) Transfection was initiated $12 \mathrm{~h}$ prior to irradiation. Values presented are means \pm SD of seven independent Kupffer cell isolations. Level of significance: $* * P<0.01$

activated. This increase of caspase 9 activity could fully be blocked by overexpressing Hsp27 in Kupffer cells (Fig. 6b). Very similar observations were made with regard to caspase 3 activity (Fig. 6c).

\section{Discussion}

The aim of the present study was to elucidate the mechanism leading to increased release of TNF- $\alpha$ of Kupffer cells after irradiation, after we had demonstrated in a previous study that the supernatant of irradiated Kupffer cells leads to sensitization of hepatocytes with regard to radiationinduced apoptosis [12]. Zhang et al. showed radiationinduced TNF- $\alpha$ production by macrophages in human lung. Interestingly, the lung macrophages themselves did not undergo apoptosis [46]. In contrast, in mouse peritoneal macrophages irradiation led to induction of apoptosis through the mitochondrial pathway [22]. In a convincing study Tasat et al. demonstrated that radiosensitivity of macrophages might increase with age. Whereas young macrophages were radioresistant, aged macrophages showed a decrease of viability after irradiation [40]. In our hands, the liver resident macrophages, the Kupffer cells, exhibit enhanced apoptosis after irradiation. Since Kupffer cells, as well as peritoneal macrophages, stay a long time in their compartment, sensitivity to radiation-induced apoptosis may be due to their aged status.

With regard to radiation-induced TNF- $\alpha$ expression in our study, we found that transcription levels did not increase in comparison to sham-irradiated cultures $(0 \mathrm{~h})$. On the protein level, TNF- $\alpha$ was found to be significantly increased in the culture medium, but appeared decreased in the cells themselves. However, when TNF- $\alpha$ content of the Kupffer cells was normalized to the actual number of cells present in the cultures, it was revealed that in the living cells TNF- $\alpha$ content did not change. This suggests that the release of TNF- $\alpha$ after irradiation may be due to apoptosis.

After irradiation, different mechanisms leading to apoptosis have been described for different cell types [4, 39]. It has also been shown that some cell types are more sensitive than others, which seems to depend on the mechanism of apoptosis induction [4, 39]. For radiation-induced apoptosis, the nucleus, the plasma membrane, and/or elements of the cytosol seem to be of special importance [4, 39]. For apoptosis-induction on DNA-level in the cell nuclei the 
transcription factor p53 plays a central role [8]. In particular, p53 negative mutants were shown to be highly radioresistant $[13,31]$. In the case of Kupffer cells, we could not detect any change of p53-gene expression due to irradiation (data not shown).

Other data demonstrated a caspase 8 dependent apoptosis pathway after irradiation. This suggests that a receptormediated pathway may be essential for radiation-induced apoptosis [42]. However, subsequent studies demonstrated that blockage of the CD95-receptor or application of FLIP did not inhibit radiation-induced apoptosis [5, 6]. In our Kupffer cell cultures, however, no activation of caspase 8 could be observed after irradiation.

At the level of the plasma membrane, ionizing radiation can cause the formation of free radicals and damage of the lipid layer of the plasma membrane. Herein, the occurrence of ceramides seem to be of special importance [44]. Ceramides may lead to integration of bax into the outer membrane leaflet of the mitochondria, with consecutive release of cytochrome $c$ and caspase 9 activation [30]. Indeed, in Kupffer cells, an involvement of bax in apoptosis induction could be suggested since there is an increase of bax expression due to irradiation and an increase of caspase 9 and caspase 3 activities, which could be blocked by downregulation of bax (resulting from an upregulation of Hsp27).

The Hsp27 has been shown to be a molecular inhibitor of apoptosis [7, 45]. It inhibits apoptosis in pathways including reactive oxygen species (ROS) indirectly by increasing cellular glutathione levels [32] and directly by neutralization of oxidized proteins [36]. Hsp27 was also shown to interact with cytochrome $c$, thereby preventing the formation of the apoptosome and activation of caspase $9[15,21]$. Above that it also can inhibit activation of caspase 3 by interaction with procaspase 3 [14] and is capable to inhibit a caspase 8 triggered activation of bid, thus leading to inhibition of the mitochondrial apoptosis pathway [35]. Fortin et al., however, demonstrated that overexpressing Hsp27 leads to thermo- and chemoresistance, but not to radioresistance of different carcinoma cell lines [20]. On the other hand, other groups demonstrated that the radioresistant DU 145 cells (human prostate carcinoma) show very high levels of Hsp27 [16, 18] and Hsp27-antisense-oligonucleotides could significantly increase radiation sensitivity [41]. Although these data support our data on Kupffer cells, we suggest an additional action of Hsp27. After irradiation, Hsp27 is downregulated and bax expression is upregulated with an increase of caspase 9 and caspase 3 activities.

After overexpressing Hsp27 in Kupffer cells, bax protein expression was drastically downregulated as observed by Western blot analysis. Furthermore, in these cells irradiation did not only lead to non reappearance of bax, but also to a complete inhibition of radiation-induced apoptosis and an inhibition of the increases of caspase 9 and caspase 3 activities. In addition, the release of TNF- $\alpha$ into the culture medium is also reduced to the level seen after sham-irradiation.

We conclude that the presented data indicate a crucial role of Hsp27 in the susceptibility of Kupffer cells to radiation-induced apoptosis. They strongly suggest that TNF- $\alpha$ release of Kupffer cells after irradiation may be due to cell death rather than active release or synthesis. Any agents that may lead to upregulation of Hsp27 in Kupffer cells could inhibit radiation-induced apoptosis of hepatocytes in vivo.

Acknowledgments This work was supported by the Deutsche Krebshilfe, Project 106760.

Open Access This article is distributed under the terms of the Creative Commons Attribution Noncommercial License which permits any noncommercial use, distribution, and reproduction in any medium, provided the original author(s) and source are credited.

\section{References}

1. Alati T, Van CM, Strom SC, Jirtle RL (1988) Radiation sensitivity of adult human parenchymal hepatocytes. Radiat Res 115:152160

2. Alati T, Eckl P, Jirtle RL (1989) An in vitro micronucleus assay for determining the radiosensitivity of hepatocytes. Radiat Res 119:562-568

3. Alati T, Van CM, Jirtle RL (1989) Radiosensitivity of parenchymal hepatocytes as a function of oxygen concentration. Radiat Res 118:488-501

4. Baatout S, Derradji H, Petitfour O, von SH, Mergeay M (2002) [Mechanisms of radio-induced apoptosis]. Can J Physiol Pharmacol 80:629-637

5. Belka C, Heinrich V, Marini P, Faltin H, Schulze-Osthoff K, Bamberg M, Budach W (1999) Ionizing radiation and the activation of caspase-8 in highly apoptosis-sensitive lymphoma cells. Int J Radiat Biol 75:1257-1264

6. Belka C, Betsch A, Marini P, Jendrossek V, Bamberg M, Budach $\mathrm{W}$ (2003) [Death inducing ligands in combination with ionizing radiation: objective and current knowledge]. Strahlenther Onkol 179:141-151

7. Brar BK, Stephanou A, Wagstaff MJ, Coffin RS, Marber MS, Engelmann G, Latchman DS (1999) Heat shock proteins delivered with a virus vector can protect cardiac cells against apoptosis as well as against thermal or hypoxic stress. J Mol Cell Cardiol 31:135-146

8. Bristow RG, Benchimol S, Hill RP (1996) The p53 gene as a modifier of intrinsic radiosensitivity: implications for radiotherapy. Radiother Oncol 40:197-223

9. Bruey JM, Ducasse C, Bonniaud P, Ravagnan L, Susin SA, az-Latoud C, Gurbuxani S, Arrigo AP, Kroemer G, Solary E, Garrido C (2000) Hsp27 negatively regulates cell death by interacting with cytochrome c. Nat Cell Biol 2:645-652

10. Charette SJ, Lavoie JN, Lambert H, Landry J (2000) Inhibition of Daxx-mediated apoptosis by heat shock protein 27. Mol Cell Biol 20:7602-7612

11. Chirgwin JM, Przybyla AE, MacDonald RJ, Rutter WJ (1979) Isolation of biologically active ribonucleic acid from sources enriched in ribonuclease. Biochemistry 18:5294-5299

12. Christiansen H, Saile B, Neubauer-Saile K, Tippelt S, Rave-Frank M, Hermann RM, Dudas J, Hess CF, Schmidberger H, Ramadori 
G (2004) Irradiation leads to susceptibility of hepatocytes to TNFalpha mediated apoptosis. Radiother Oncol 72:291-296

13. Clarke AR, Purdie CA, Harrison DJ, Morris RG, Bird CC, Hooper ML, Wyllie AH (1993) Thymocyte apoptosis induced by p53dependent and independent pathways. Nature 362:849-852

14. Concannon CG, Orrenius S, Samali A (2001) Hsp27 inhibits cytochrome c-mediated caspase activation by sequestering both procaspase-3 and cytochrome c. Gene Expr 9:195-201

15. Concannon CG, Gorman AM, Samali A (2003) On the role of Hsp27 in regulating apoptosis. Apoptosis 8:61-70

16. Cornford PA, Dodson AR, Parsons KF, Desmond AD, Woolfenden A, Fordham M, Neoptolemos JP, Ke Y, Foster CS (2000) Heat shock protein expression independently predicts clinical outcome in prostate cancer. Cancer Res 60:7099-7105

17. de Leeuw AM, McCarthy SP, Geerts A, Knook DL (1984) Purified rat liver fat-storing cells in culture divide and contain collagen. Hepatology 4:392-403

18. DeWeese TL, Shipman JM, Dillehay LE, Nelson WG (1998) Sensitivity of human prostatic carcinoma cell lines to low dose rate radiation exposure. J Urol 159:591-598

19. Estler HC, Grewe M, Gaussling R, Pavlovic M, Decker K (1992) Rat tumor necrosis factor-alpha. Transcription in rat Kupffer cells and in vitro posttranslational processing based on a PCR-derived cDNA. Biol Chem Hoppe Seyler 373:271-281

20. Fortin A, Raybaud-Diogene H, Tetu B, Deschenes R, Huot J, Landry $\mathrm{J}$ (2000) Overexpression of the $27 \mathrm{KDa}$ heat shock protein is associated with thermoresistance and chemoresistance but not with radioresistance. Int J Radiat Oncol Biol Phys 46:1259-1266

21. Garrido C, Bruey JM, Fromentin A, Hammann A, Arrigo AP, Solary E (1999) Hsp27 inhibits cytochrome c-dependent activation of procaspase-9. FASEB J 13:2061-2070

22. Hernandez-Flores G, Gomez-Contreras PC, Dominguez-Rodriguez JR, Lerma-Diaz JM, Ortiz-Lazareno PC, Cervantes-Munguia R, Sahagun-Flores JE, Orbach-Arbouys S, Scott-Algara D, BravoCuellar A (2005) Gamma-irradiation induced apoptosis in peritoneal macrophages by oxidative stress. Implications of antioxidants in caspase mitochondrial pathway. Anticancer Res 25:4091-4100

23. Jirtle RL, Michalopoulos G, McLain JR, Crowley J (1981) Transplantation system for determining the clonogenic survival of parenchymal hepatocytes exposed to ionizing radiation. Cancer Res 41:3512-3518

24. Jirtle RL, McLain JR, Strom SC, Michalopoulos G (1982) Repair of radiation damage in noncycling parenchymal hepatocytes. $\mathrm{Br} \mathrm{J}$ Radiol 55:847-851

25. Jirtle RL, DeLuca PM, Hinshaw WM, Gould MN (1984) Survival of parenchymal hepatocytes irradiated with $14.3 \mathrm{MeV}$ neutrons. Int J Radiat Oncol Biol Phys 10:895-899

26. Jirtle RL, Michalopoulos G, Strom SC, DeLuca PM, Gould MN (1984) The survival of parenchymal hepatocytes irradiated with low and high LET radiation. Br J Cancer Suppl 6:197-201

27. Kammanadiminti SJ, Chadee K (2006) Suppression of NF-kappaB activation by Entamoeba histolytica in intestinal epithelial cells is mediated by heat shock protein 27. J Biol Chem 281:26112-26120

28. Knittel T, Aurisch S, Neubauer K, Eichhorst S, Ramadori G (1996) Cell-type-specific expression of neural cell adhesion molecule (N-CAM) in Ito cells of rat liver. Up-regulation during in vitro activation and in hepatic tissue repair. Am J Pathol 149:449-462

29. Laemmli UK (1970) Cleavage of structural proteins during the assembly of the head of bacteriophage T4. Nature 227:680-685
30. Liao WC, Haimovitz-Friedman A, Persaud RS, McLoughlin M, Ehleiter D, Zhang N, Gatei M, Lavin M, Kolesnick R, Fuks Z (1999) Ataxia telangiectasia-mutated gene product inhibits DNA damage-induced apoptosis via ceramide synthase. J Biol Chem 274:17908-17917

31. Lowe SW, Schmitt EM, Smith SW, Osborne BA, Jacks T (1993) p53 is required for radiation-induced apoptosis in mouse thymocytes. Nature 362:847-849

32. Mehlen P, Schulze-Osthoff K, Arrigo AP (1996) Small stress proteins as novel regulators of apoptosis. Heat shock protein 27 blocks Fas/APO-1- and staurosporine-induced cell death. J Biol Chem 271:16510-16514

33. Neubauer K, Knittel T, Armbrust T, Ramadori G (1995) Accumulation and cellular localization of fibrinogen/fibrin during short-term and long-term rat liver injury. Gastroenterology 108:1124-1135

34. Pandey P, Farber R, Nakazawa A, Kumar S, Bharti A, Nalin C, Weichselbaum R, Kufe D, Kharbanda S (2000) Hsp27 functions as a negative regulator of cytochrome c-dependent activation of procaspase-3. Oncogene 19:1975-1981

35. Paul C, Manero F, Gonin S, Kretz-Remy C, Virot S, Arrigo AP (2002) Hsp27 as a negative regulator of cytochrome $\mathrm{c}$ release. Mol Cell Biol 22:816-834

36. Preville X, Salvemini F, Giraud S, Chaufour S, Paul C, Stepien G, Ursini MV, Arrigo AP (1999) Mammalian small stress proteins protect against oxidative stress through their ability to increase glucose-6-phosphate dehydrogenase activity and by maintaining optimal cellular detoxifying machinery. Exp Cell Res 247:61-78

37. Rane MJ, Pan Y, Singh S, Powell DW, Wu R, Cummins T, Chen Q, McLeish KR, Klein JB (2003) Heat shock protein 27 controls apoptosis by regulating Akt activation. J Biol Chem 278:2782827835

38. Schwartz RJ, Haron JA, Rothblum KM, Dugaiczyk A (1980) Regulation of muscle differentiation: cloning of sequences from alphaactin messenger ribonucleic acid. Biochemistry 19:5883-5890

39. Szumiel I (1994) Ionizing radiation-induced cell death. Int J Radiat Biol 66:329-341

40. Tasat DR, Mancuso R, Evelson P, Polo JM, Llesuy S, Molinari B (2002) Radiation effects on oxidative metabolism in young and aged rat alveolar macrophages. Cell Mol Biol (Noisy.-le-grand) 48:529-535

41. Teimourian S, Jalal R, Sohrabpour M, Goliaei B (2006) Downregulation of Hsp27 radiosensitizes human prostate cancer cells. Int J Urol 13:1221-1225

42. Tepper AD, de VE, van Blitterswijk WJ, Borst J (1999) Ordering of ceramide formation, caspase activation, and mitochondrial changes during. J Clin Invest 103:971-978

43. Towbin H, Staehelin T, Gordon J (1979) Electrophoretic transfer of proteins from polyacrylamide gels to nitrocellulose sheets: procedure and some applications. Proc Natl Acad Sci USA 76:4350-4354

44. Verheij M, Bartelink H (2000) Radiation-induced apoptosis. Cell Tissue Res 301:133-142

45. Wagstaff MJ, Collaco-Moraes Y, Smith J, de Belleroche JS, Coffin RS, Latchman DS (1999) Protection of neuronal cells from apoptosis by Hsp27 delivered with a herpes simplex virus-based vector. J Biol Chem 274:5061-5069

46. Zhang M, Kong F, Qian J, Chen M, Lawrence TS (2005) Radiation-induced lung apoptosis is mediated by TNF-alpha action. Int J Radiat Oncol Biol Phys 63:S83-S84 